UNIVALI

UNIVERSIDADE DO VALE DO ITAJAI

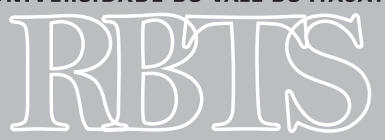

Revista Brasileira de Tecnologias Sociais
1 Bacharel em Direito (2013) Universidade do Vale do Itajaí UNIVALI. Cursando Mestrado Profissional em Gestão de Políticas Públicas (2016/17), Universidade do Vale do Itajaí - UNIVALI, município de Itajaí$\mathrm{SC}$, Brasil.

2 Doutora (2009) e Mestre (2002) em Antropologia Social pela Universidade Federal de Santa Catarina-UFSC, município de Florianópolis-SC, Brasil. Graduada em Psicologia na Universidade do Vale do Itajaí, UNIVALI (1999). Professora titular no Mestrado em Gestão de Políticas Públicas - UNIVALI, município de Itajaí-SC, Brasil.

3 Graduação em Direito pela Universidade de São Paulo (1983). Mestrado em Direito Econômico e Financeiro pela Universidade de São Paulo (1993) e Doutorado em Direito, Estado e Sociedade pela Universidade Federal de Santa Catarina (2004). Professor adjunto da Universidade do Estado de Santa Catarina (UDESC).

4 Filósofa. Mestre em Educação (FURB) e Doutora em Teologia (EST). Pesquisadora e Professora titular no Mestrado em Gestão de Políticas Públicas - UNIVALI, município de ItajaíSC, Brasil.

\section{UMA ETNOGRAFIA NUM PRESÍDIO FEMININO NO SUL DO BRASIL: MULHERES-MÃES E SEUS FILHOS NO CÁRCERE}

\section{AN ETHNOGRAPHY IN A FEMALE PRISONER IN THE SOUTH OF BRAZIL: INCARCERATED WOMEN- MOTHERS AND THEIR CHILDREN}

\author{
Aline Perussolo ${ }^{1}$ \\ Micheline Ramos de Oliveira ${ }^{2}$ \\ FÁbio Pugliesi ${ }^{3}$ \\ Maria Glória Dittrich ${ }^{4}$
}

Resumo: Com base num discurso crítico sobre a maternidade (BADINTER, 1980) elegemos como foco desta pesquisa uma discussão sobre a maternidade no interior de presídios femininos e o papel do Estado e de políticas públicas, que deveriam humanizar esta experiência. Nosso campo se deu numa penitenciária feminina situada no sul do Brasil, nossas interlocutoras foram mães que criam seus filhos dentro do presídio. Além delas, entrevistamos a diretora do presídio e agentes prisionais. O método utilizado foi a pesquisa qualitativa, elaborada por meio de uma etnografia e de entrevistas livres formatadas em narrativas biográficas das mulheres em foco. Diante da barbárie do sistema prisional brasileiro, um berçário apareceu como um oásis, numa tentativa de humanização de um lugar antes fétido e inapropriado para o abrigo de qualquer adulto e, neste caso, de crianças em idade de amamentação e suas mães. Uma política pública customizada, diante de um contexto precário, com certeza não resolverá os problemas estruturais de nossas prisões, mas desponta como um sinalizador que iniciativas aparentemente pequenas, modificam a vida de uma parcela da população e, nesta discussão num sentido mais amplo, demonstra que as maternidades e suas vicissitudes devem ser tratadas como relações construídas contextual e historicamente e respeitadas, como no caso do presídio, pelos Estados e suas políticas públicas.

PALAVRAS-CHAVE: Maternidade no cárcere; Berçário; Presídio feminino.

ABSTRACT: Based on a critical discourse on motherhood (BADINTER, 1980) we elected, as the focus of this research, a discussion about maternity within women's prisons and the role of the State and public policies, which are supposed to humanize this experience. Our field of study was a women's penitentiary located in the South of Brazil. Our interlocutors were mothers who were raising their children inside the prison. We also interviewed the director of the prison and prison officers. The method used was qualitative research, elaborated through an ethnography and interviews with 
open-ended questions, formatted into biographical narratives of the women. Amidst the barbarity of the Brazilian prison system, a nursery appeared as an oasis, in an attempt to humanize a place that was fetid and inappropriate to shelter any adult, and in this case, children of breastfeeding age and their mothers. A customized public policy, faced with a precarious context, will certainly not solve the structural problems of our prisons, but it stands out as a signal that apparently small initiatives can improve the lives of a portion of the population, and, in this discussion in a broader sense, shows that maternities and their vicissitudes should be seen as contextually and historically constructed relations, and respected, as in the case of the prison, by the states and their public policies.

KEYWORDS: Maternity in the prison; Nursery; Female prison. 


\section{INTRODUÇÃO}

O desempenho do Brasil é regulado por legislações arcaicas, uma delas é a gestão prisional. Conhecemos inúmeras problemáticas que ocorrem constantemente no país, e nesta discussão focalizaremos a maternidade no cárcere, ou seja, mulheres que estão encarceradas no presídio feminino, juntamente com seus filhos em idade de amamentação.

As consequências da vida no cárcere já foram relatadas por alguns pesquisadores, mas os estudos acerca do aprisionamento de crianças com suas mães que estão cumprindo pena em presídios femininos são quase inexistentes ou escassos.

Em relação a esta questão, podemos dizer que o sofrimento na infância marca o ser humano profundamente, muitas vezes é preciso uma vida inteira para conhecer os medos e as angústias causados por estigmas da infância (BADINTER, 1980, p.38). Foi-nos relatado que algumas crianças que acabaram de aprender a andar, antes da existência do berçário, e de sua permanência no interior das celas juntamente com as presidiárias mulheres, foram condicionadas a erguer os braços para serem algemadas tal qual suas mães, embora o ato de serem algemadas nunca tenha sido realizado.

Neste interim, por meio de uma pesquisa de campo realizada em 2016 numa penitenciária no sul do Brasil, averiguamos a existência de um modelo de berçário que, a princípio, contraria a realidade dos presídios brasileiros, instigando-nos a problematizar a humanização de Políticas Públicas Sociais para mães encarceradas, por meio de um estudo etnográfico do cotidiano e das narrativas biográficas de mulheres e de seus filhos no ambiente carcerário.

O método utilizado foi a pesquisa qualitativa, um método de investigação científico que foca no caráter subjetivo da situação analisada, estudando as suas particularidades e as experiências individuais. Fizemos uso da etnografia, compreendida aqui como uma descrição densa da realidade (GEERTZ, 1978, p.54), explanando a produção de sentido dos interlocutores e a própria subjetividade das pesquisadoras, compondo o processo arquitetônico da pesquisa e dos seus resultados. As narrativas biográficas, que são as entrevistas livres com as mulheres em foco, investigaram os percursos e os trajetos individuais e/ou sociais de cada uma delas, a partir de suas próprias falas e o indispensável diário de campo, instrumento de registro e análise de dados de cada visita realizada na penitenciária.

As narrativas de nossas interlocutoras nos dão pistas para pensar como as trajetórias sociais contemplam nas suas tramas diferentes itinerários urbanos, nos quais "o ser mãe no presídio" participa do processo de construção de experiências violentas no corpo de suas identidades narrativas de mulheres atravessadas por violências. Essas mulheres dão um ponto de vista desse processo cujos deslocamentos pela cidade, em sua condição de gênero, até adentrarem no presídio, obriga-lhes a pensar as formas de romper com o lugar de vítima que a condição feminina ocupa no contexto das violências urbanas.

Aqui, o conceito de campo de possibilidades é fundamental e, nesse contexto, sem dúvida, a memória das próprias violências acomodadas na memória coletiva dos presídios femininos. Assim, a força das narrativas biográficas de nossas interlocutoras mulheres nos permitiram pensar alguns elementos significativos da "teatralidade" das violências ordinárias vividas em seus itinerários urbanos, prioritariamente dentro do presídio, que passam a ser incorporadas às suas formas de enfrentar sua condição de vítimas no contexto do cárcere e de ser mãe no cárcere. 


\section{NARRATIVAS BIOGRÁFICAS DE MULHERES DETENTAS E AGENTES PRISIONAIS}

Em nosso primeiro dia de campo, encontramos a diretora do presídio feminino. Em sua primeira fala, ela demonstra a dificuldade de dirigir um espaço no cárcere habitado por mulheres, mas construído por homens e para homens, e até então coordenado também por homens. Retiramos um fragmento de nosso diário de campo:

Quando cheguei ao presídio, percebi que a cultura machista e todas as violências grudadas a elas estavam explícitas... A começar pela arquitetura e o tratamento dado às mulheres pelos agentes e pelas agentes em geral. As crianças ficavam dentro das celas com suas mães... Era de cortar o coração, foi aí que tivemos a ideia de transformar um espaço mal aproveitado do presídio num berçário com camas de solteiro e berços, e decorado para receber as crianças para que essas mães e seus filhos possam ter uma vida mais digna aqui dentro do presídio... Elas têm televisão, uma pequena cozinha, banheiro e um pequeno pátio para tomar sol. Isso é o mínimo, mas já enxergamos diferença na vida dessas pessoas, principalmente nas crianças que adoecem menos... No dia a dia aqui a gente vê como as mulheres são tratadas, inclusive eu, com certo sarcasmo, além das piadas machistas de toda ordem. Me sinto lutando por uma causa, como mulher, penso que tenho essa responsabilidade e me sinto capaz (Diretora do presídio feminino, sul do Brasil, 2016).

Em outra conversa, agora com uma detenta que sofreu preconceito por ser mulher dentro do presídio, foi-nos revelado um pouco de sua história. Foragida, decidiu entregar-se na delegacia mais próxima de sua casa, estava grávida de oito meses; o marido, que tinha lhe abandonado, estava foragido também, ela temia ser presa na maternidade no dia do parto e nos narrou que se arrependeu de ter se entregado, após ter recebido a roupa laranja do presídio, mas que agora compreende que foi a melhor atitude a ter tomado, está perto de sua criança, cuidando e acompanhando seu crescimento, situação que desconheceria caso fosse presa na maternidade. Ela nos relatou que viver no presídio dentro do berçário com seu filho, antes que numa cela convencional, ameniza em certo grau seu sofrimento e a faz sentir mais valorizada.

A fala da diretora e da detenta revelam a tentativa de um exercício para romper com os modelos construídos para os papéis de gêneros e suas relações hierárquicas com base em valores patriarcais que orientam a sociedade brasileira em geral e são indícios de transformações de seus estilos de vida e visão de mundo e que se devem, em grande parte, às suas inserções progressivas. A primeira, ocupando um cargo hierárquico geralmente ocupado por homens, a direção de um presídio; e a segunda, por ter acesso a um "benefício”, o berçário dentro do presídio, que a dignifica, pelo menos, pontualmente, na condição a qual lhe acontece viver.

Nesse sentido, podemos aderir à ideia de que essa duração ou não da violência na vivência dessas mulheres gravita em torno de "constelações de imagens" grudadas a "certos protocolos normativos das representações imaginárias [...] agrupados em torno dos esquemas originais”, os quais podemos denominar aqui de "estruturas" (DURAND, 2002, p. 63). Aqui, as constelações de imagens a partir das quais podemos interpretar a reinvenção de si das mulheres em foco são habitadas pelos temas do "puro e impuro", da "santa e da prostituta", da "vítima e do algoz", do "destino e do antidestino" e da "honra”, como poderemos visualizar também nas demais falas. 
Estruturas que, por apresentarem formas dinâmicas, ou seja, estarem sujeitas "a transformações por modificações de um dos termos", constituem "modelos" que podem servir tanto para a classificação dos episódios violentos e para a interpretação de suas causas e efeitos quanto para "modificação do campo imaginário" (DURAND, 2002, p. 63), como ocorre quando os indivíduos que experienciaram conflitos-violentos conseguem, finalmente, modificar o sentido dado à violência, como dos dois depoimentos vistos anteriormente.

Infelizmente essas experiências ímpares não nos removem de questionamentos como entender essa violência causada pelo sistema político e econômico de um país que diariamente desvela corruptos eleitos pelo povo brasileiro. Estar entre a liberdade e o cárcere para uma mulher com filho(a) é diariamente uma luta contra a loucura e o anseio de estar livre, além disso, as mulheres sofrem a punição do Estado, que pouco se impõe com um descaso da situação, a não ser em casos atípicos, como ocorreram alguns dias atrás. Trata-se do caso da mulher do Sérgio Cabral, ex-governador do Rio de Janeiro, famoso caso que repercutiu na mídia social. Para ela o artigo 318 do $\mathrm{CPP}^{1}$ foi aplicado. Depois de algum tempo presa preventivamente por suposto crime no sistema de corrupção revelado na operação Calicute ${ }^{2}$, foi liberada a cumprir prisão domiciliar por ter filhos dependentes.

O contexto político e caótico que vivenciamos demonstra o descaso do Estado com mães, gestantes e crianças no cárcere, continuando a desvelar históricos punitivos similares à obra Vigiar e Punir, de Michael Foucault (1987). Naquela época a punição advinha de um show na praça. Inimagináveis torturas eram realizadas, havia plateia para assistir à purgação. No sistema carcerário atual pouca mudança ocorreu, nosso código penal ainda é da década de 40, e da:

... privação de liberdade à punição vai-se tornando, pois, a parte mais velada do processo penal, provocando várias conseqüências: deixa o campo da percepção quase diária e entra no da consciência abstrata; sua eficácia é atribuída à sua fatalidade não à sua intensidade visível; a certeza de ser punido é que deve desviar o homem do crime e não mais o abominável teatro; a mecânica exemplar da punição muda as engrenagens. Por essa razão, a justiça não mais assume publicamente a parte de violência que está ligada a seu exercício. (FOUCAULT, 1987, p.13).

Narrativas de detentas versam sobre preconceitos relacionados diretamente à misoginia. Muitas mulheres entrevistadas disseram sofrer violência por meio de discursos que naturalizam o machismo e, por se sentirem culpadas e por medo de se defender, não retrucam tais violências, como: "Me chamam de vadia e dizem que a culpa de meu filho estar aqui é só minha, fico com raiva quando ouço isso, mas não consigo dizer nada... me sinto confusa..." (detenta do presídio feminino, 2016) ou "Riem de meu uniforme laranja, me colocam cheirando a parede como se fosse criança, e dizem que sou perigosa, sou uma bruxa, sou mulher, falam que sou um perigo para meu filho..." (detenta do presídio feminino, 2016).

A condição de encarceramento, neste contexto, imporia limites no processo de condução dos jogos de memória e seu poder conciliador, forçando a naturalizar a violência num estilo de vida, seguida de uma visão de mundo em que o risco ocupa parte central da argumentação. Nesse

1 Art. 318. Poderá o juiz substituir a prisão preventiva pela domiciliar quando o agente for: (Redação dada pela Lei ${ }^{\circ} 12.403$, de 2011 ). Incisos: III - imprescindível aos cuidados especiais de pessoa menor de 6 (seis) anos de idade ou com deficiência; (Incluído pela Lei $\mathrm{n}^{\circ}$ 12.403, de 2011). IV - gestante; (Redação dada pela Lei nº 13.257, de 2016).

V - mulher com filho de até 12 (doze) anos de idade incompletos; (Incluído pela Lei no 13.257, de 2016).

2 G1.http://g1.globo.com/rio-de-janeiro/noticia/presa-em-dezembro-adriana-ancelmo-vai-para-prisao-domiciliar.ghtml. 
contexto, o tema do livro de Elias (1998, p.27) "Envolvimento e Alienação" nos parece importante de ser resgatado na medida em que o medo dos outros se torna o mesmo medo de si.

Aqui é importante frisar que, em alguns casos, para as mulheres em suas trajetórias sociais e itinerários urbanos com passagem por presídios, na condição de detentas, a criminalização da cidade e na cidade é vista como a única forma de continuar a viver. Assim, é nessa mesma cidade em que ela vivencia a rejeição e a marginalização que ela reconhece o meio para sua sobrevivência e a sobrevivência de sua prole, pautando sua trajetória por reconhecidos itinerários urbanos demarcados pela criminalização.

Esses territórios são também reconhecidos por boa parte de agentes prisionais, que utilizam deste saber, mesmo que inconscientemente, para conduzir seus comportamentos preconceituosos contra as mulheres, lembrando que as relações assimétricas e simétricas de gênero, em seu sentido amplo, devem ser consideradas como produtos da historicidade e da concretude de ações humanas, já que a "permanência ou não" de uma "hierarquia de gênero" deve ser aprendida por meio de uma leitura crítica reflexiva que leve à memória da cotidianidade destas hierarquias e seu "peso" do fato social e político, incluindo nosso estudo de caso no presídio feminino.

\section{O COTIDIANO DE MULHERES ENCARCERADAS}

O mínimo encontrado no berçário da penitenciária foram os berços, as camas e um quarto simples com cozinha, banheiro e um pequeno pátio para estender roupas e tomar sol, uma exceção de dignidade para as mães e crianças, pois em muitas penitenciárias a situação é insustentável, mãe e filho(a) dividem a mesma cama numa cela úmida e escura, miolo de pão que vira absorvente, tumores que estouram nos corpos de detentas por falta de atendimento médico, como relata a matéria Mães do cárcere, publicada na Revista Radis (COMUNICAÇÃO E SAÚDE, 2017 p.17).

Narrativas trazem as dificuldades de atendimento pelo SUS, por clínicas particulares e pelo atendimento no Pronto Atendimento. A situação de pronto atendimento, em que o médico de plantão diz “a presa não entra”, no caso para o atendimento para mãe e criança, enfermeiros e estagiários de plantão, alegando o constrangimento que uma presa causa às demais pessoas que estão esperando pelo atendimento, pelo pretenso motivo de chegar numa viatura de polícia, algemada e com uniforme carcerário.

Ainda, narrativas que denunciam casos de clínicas particulares enviarem carta de recomendação de atendimento à gerência do presídio, exigindo que as detentas que custeassem exames particulares chegassem nas viaturas policiais em horários diferenciados do comercial e pelos fundos das clínicas, para não gerarem desconforto aos clientes que aguardavam atendimento e para evitar cancelamentos de consultas, o que já estava ocorrendo. Para completar a recomendação, ameaçavam não atender às detentas, caso não cumprissem o pedido.

As narrativas anteriores foram feitas pela diretora do presídio, que narrava os fatos de forma indignada. Sua atitude foi acionar a advogada da penitenciária para responder à carta de recomendação, mencionando que facilitaria com o pedido dos horários e a chegada pelos fundos, mas que não admitiria o não atendimento às detentas, caso ocorresse, denunciaria o caso para o Ministério Público.

As narrativas revelam que, para além da judicialização, faz-se necessário considerar todos os aspectos do que podemos chamar a eficácia social da destruição (MAFFESOLI; BRUSTON, 
1987, p. 86). A marginalidade, por exemplo, é uma forma de reprodução social. O desvio, a anomia se integram ao funcionamento global de um conjunto social, claramente exposto nas narrativas das mulheres e seu precário cotidiano, cuja continuidade de uma vida marginal se dá por meio das engrenagens institucionais da sociedade, tal qual o não acesso ao atendimento na saúde e bens materiais básicos para o bem viver das presas e de seus filhos.

Nesse sentido, as discussões de Maffesoli e Bruston (1987) podem corroborar com a percepção de que, ao longo da pesquisa, as narrativas retiradas do campo trouxeram consigo características em comum, reveladoras de um “viver" no mundo urbano brasileiro contemporâneo, demarcado por experiências de violências.

Aqui, a categoria "conflito-violento" nos inspira em Simmel (1965, p. 56) e Velho (2008, p. 21), toma forma quando se pretende "insistir na necessidade", cada vez mais premente, de perceber uma teia de acontecimentos que se constroem no campo "desconhecido" e "maldito" da violência e qual sua "eficácia” nas redes de sociabilidade dos atores que a praticam. A narrativa de outra interlocutora pode ser emblemática: "sempre apanhei na rua, depois apanhei em casa de meu marido, depois de meu amante, agora no presídio... Na primeira vez que saí daqui tentei emprego, não consegui por ser ex-presidiária, voltei para o tráfico de drogas, agora estou presa novamente e grávida... Me sinto menos mal, já que aqui no berçário me sinto mais gente” (detenta do presídio feminino, 2016).

As narrativas destas mulheres revelam a violência cometida pela sociedade antes, durante e após o cárcere. A experiência da diretora do presídio desvela as dificuldades encontradas no dia a dia penitenciário. As narrativas das mulheres detentas afirmam a violência acometida por familiares, pela sociedade e pelo sistema punitivo do Estado.

Consideramos, portanto, que a "memória da cotidianidade e a memória coletiva" para o caso do estudo de narrativas biográficas sobre práticas de violências e humanização são dois eixos necessários de interpretação desse fenômeno que, diante de rupturas vividas por seus sujeitos, permite que compreendamos a forma como se propaga o fenômeno da violência na sociedade e sua instauração em múltiplos ambientes, principalmente o carcerário no interior das trajetórias sociais dos sujeitos contemporâneos (ROCHA; ECKERT, 2000, p. 99).

\section{CONSIDERAÇÕES FINAIS}

A conjunção da violência e da razão é potencialmente tensa e, graças a essa conjunção, a violência pode tornar-se terror. É a partir daí que começa um desencadeamento da violência que nada pode diminuir, visto que, por sua racionalização, ela se difunde, e o aumento cada vez maior da criminalidade, da insegurança, faz parte de sua instrumentalização.

Particularizando a violência, ou seja, destacando-a de sua essência ritualística, o que é luta de uns contra os outros, tende a se fragmentar em luta de cada um contra todos; pequena guerrilha fundada na atomização, que faz com que a violência se dilua em agressividade mesquinha e cotidiana (OLIVEIRA, 2009, p. 236).

Nesse sentido, podemos dizer que os atos de violências dessas mulheres como vítimas e/ou algozes passam por uma ordenação nos jogos de suas memórias, cuja ordem coletiva das violências, agressões, abusos, e demais fenômenos dessa ordem, se acomodam junto com o fator tempo, tornando-as partes integrantes desse espetáculo triste de sobreviventes da pobreza, da 
marginalidade, do desemprego, do desamparo das instituições socais mais básicas, como a escola, a creche, entre outras.

Atiradas à própria sorte, nossa democracia vai culpabilizá-las por seus destinos, como se, em algum momento de suas vidas, realmente tivessem tido a chance de sair desse mundo onde os atos de conflito-violento atrelam-nas a um destino no interior de idas e vindas à prisão.

Voltamos um pouco às narrativas, cuja frase de desvelamento sobrescreve nas entrelinhas: “se a sociedade não insere a presa, como quer reinseri-la?”.

A investigação das trajetórias sociais das mulheres encarceradas revela que as condições de vida precárias dessas mulheres passaram paulatinamente a se conformarem em estilos de vida e visões do mundo em que o conflito-violento torna-se código de emoções para ordenação de um si - mesmo. Refletir sobre as matérias de lembrança (fome, pobreza, abandono, miséria) que as narrativas trouxeram nesse contex to memorial significa pensar o lugar do cárcere na forma como essas mulheres passam a recompor suas trajetórias de vida.

Este estudo tenta demonstrar o descaso do Estado com o sistema carcerário, numa construção feita por e para homens, em que a mulher tenta se adaptar e sequer imagina que encontrará tamanha dificuldade para criar uma criança em condições precárias e não humanizadas, inúmeros problemas num ambiente sombrio e asqueroso. Nosso desafio é imenso, é preciso trabalhar um discurso de desconstrução para mostrar à sociedade que a prisão não é um local apropriado para efetivar a saúde, a educação e a cultura de homens, nem de mulheres e muitos menos de crianças.

Da situação carcerária caótica que vivemos, um dos motivos concretos que nos faz reforçar a convicção para essa desconstrução de pensamento e atitudes da sociedade é o berçário idealizado pela direção de uma mulher nessa penitenciária, de celas úmidas e escuras, a qual planejou e vem se construindo melhorias para esse ambiente hostil, trazendo o mínimo de humanização para um presídio feminino que recebe mulheres e crianças.

\section{REFERÊNCIAS}

BADINTER, E. Um amor conquistado: O mito do amor materno. Rio de Janeiro: Nova Fronteira, 1980. COMUNICAÇÃO E SAÚDE. Mães do cárcere. Como é a vida das mulheres grávidas, que dão à luz e amamentam nas prisões brasileiras. Revista Radis, nº 172, Fio Cruz, jan/2017.

DURAND, G. Les structures anthropologiques de l'imaginaire. Paris: Dunod, 2002.

ELIAS, N. Envolvimento e alienação. Rio de Janeiro: Bertrand Brasil, 1998.

FOUCAUlT, M. Vigiar e Punir: nascimento da prisão. Petrópolis: Vozes, 1987.

GEERTZ, C. A Interpretação das Culturas. Zahar: Rio de Janeiro, 1978.

MAFFESOLI, M; BRUSTON, André. Dinâmica da violência. São Paulo: Revista dos Tribunais, 1987.

OLIVEIRA, M. R de. No Limiar da Memória: estudo antropológico sobre mulheres e violências na metrópole contemporânea. 2009. 293f. Tese (Doutorado em Antropologia Urbana) - Universidade Federal de Santa Catarina, Florianópolis, 2009.

Perussolo et. al. 
ROCHA, A. L. C.; ECKERT. C. A memória como espaço fantástico. Iluminuras, Porto Alegre, vol. 1, n.1, p.02-15, 2000.

SIMMEL, G. On conflict. Theories of Society. Nova York: The Free Press, 1965.

VELHO, G. Rio de Janeiro: cultura, política e conflito. Rio de Janeiro: Jorge Zahar, 2008. 